ASTHMA

\title{
Childhood factors associated with asthma remission after 30 year follow up
}

\author{
J M Vonk, D S Postma, H M Boezen, M H Grol, J P Schouten, G H Koëłer, J Gerritsen
}

Thorax 2004:59:925-929. doi: 10.1136/thx.2003.016246

See end of article for authors' affiliations

.....................

Correspondence to: JM Vonk, PhD, Department of Epidemiology, University of Groningen, P O Box 196,9700 AD Groningen, The Netherlands; j.m.vonk@ med.rug.nl

Received 10 October 2003 Accepted 15 July 2004

\begin{abstract}
Background: Factors contributing to either "complete" or "clinical" remission of asthma are important to know since there is no cure for the disease.

Methods: A cohort of 119 allergic asthmatic children was examined three times with a mean follow up of 30 years. They were aged 5-14 years at visit 1 (1966-9), 21-33 years at visit 2 (1983-6), and 32-42 years at visit 3 (1995-6). Complete remission of asthma at visit 3 was defined as no asthma symptoms, no use of inhaled corticosteroids, normal lung function ( $F E V_{1}>90 \%$ predicted), and no bronchial hyperresponsiveness $\left(\mathrm{PC}_{10}>16 \mathrm{mg} / \mathrm{ml}\right)$. Clinical remission was defined as no asthma symptoms and no use of inhaled corticosteroids.

Results: $22 \%$ of the group was in complete remission of asthma at visit 3 and a further $30 \%$ was in clinical remission (total 52\%); $57 \%$ of subjects in clinical remission had bronchial hyperresponsiveness and/or a low lung function. Logistic regression analyses showed that a higher $\mathrm{FEV}_{1}$ in childhood and more improvement in $\mathrm{FEV}_{1}$ from age 5-14 to 21-33 were associated with both complete and clinical asthma remission at age $32-42$.

Conclusions: Complete remission of asthma was present in a small subset of asthmatics while half the subjects showed clinical remission. Both complete and clinical remission were associated with a higher lung function level in childhood and a higher subsequent increase in $\mathrm{FEV}_{1}$. These results support the view that defining remission only on the basis of symptoms and medication use will overlook subjects with subclinical active disease and possibly associated airway remodelling.
\end{abstract}

$\mathrm{T}$ he paramount aim of asthma management is complete cure. So far, this cannot be achieved with the available treatment. It is therefore important to know which childhood and early adult factors contribute to the best attainable outcome-namely, remission of asthma. Only a few population based studies on the natural history and outcome of asthma are available, ${ }^{1-7}$ defining remission of asthma generally as absence of respiratory symptoms and asthma medication use. Martin et al found 20\% of a group of individuals who frequently wheezed in childhood to be symptom free at age 21 , as were $50 \%$ of a group that wheezed infrequently in childhood. ${ }^{1}$ Twenty one years later, at a mean age of 42 years, these percentages were slightly higher (about $30 \%$ and $55 \%$, respectively). ${ }^{2}$ Another population-based study on 2300 subjects aged 10-79 years reported that $22 \%$ of the 136 subjects with active asthma were symptom free after a follow up of 9.4 years. ${ }^{3}$ The highest remission rates were found in the second decade of life. A recent study reported that $25 \%$ of a longitudinal population based cohort had persistent or relapsing childhood wheezing by the age of 26 years. Factors predicting persistence or relapse were childhood sensitisation to house dust mites, childhood bronchial hyperresponsiveness (BHR), female sex, current smoking, and early age at onset. ${ }^{4}$

Studies in asthma patients have shown similar results with $24 \%$ of a group of 406 asthmatic subjects aged 8-12 years being symptom free at age 21-29. ${ }^{5}$ Panhuysen et al studied 181 asthma patients aged 13-44 years at enrolment and showed that, although $41 \%$ did not report asthma symptoms, only $11 \%$ were in remission of asthma when studied 25 years later (remission being defined as absence of symptoms and BHR, and $\mathrm{FEV}_{1}>90 \%$ predicted). ${ }^{6}$ Furthermore, Boulet et al showed that asthma patients in remission, defined as absence of symptoms and no use of asthma medication for 2 years, still had BHR, significant reversibility, and lower lung function than healthy individuals. ${ }^{7}$ Thus, asthma symptoms and asthma treatment may not be useful to determine whether an individual outgrows asthma. This idea is supported by findings of van den Toorn et al who showed ongoing airway inflammation in bronchial biopsies taken from asthma patients who no longer had respiratory symptoms nor used asthma medication. ${ }^{8}$

The aim of this follow up study over 30 years was to identify factors that are associated with remission of asthma in a group of 119 allergic asthmatic children aged 5-14 years at initial investigation. Given the above background, two different definitions of asthma remission were used.

\section{METHODS}

\section{Study design and patients}

We re-examined a cohort of 119 allergic asthmatic children who were admitted to the outpatient clinic of the paediatric pulmonology department of the University Hospital of Groningen between 1966 and 1969 (visit 1, age 5-14 years). ${ }^{9}$ Follow up data were collected between 1983 and 1986 (visit 2, age 21-33 years) and between 1995 and 1996 (visit 3, age 32-42 years). The medical ethics committee of the University Hospital of Groningen approved the study, and all participants gave a written informed consent. Inclusion criteria at visit 1 were having doctor's diagnosed asthma in a stable condition, parental informed consent for a 5 day stay in hospital, and being able to perform technically satisfactory lung function tests. Exclusion criteria were the presence of specific respiratory diseases (cystic fibrosis or tuberculosis) or other seriously interfering diseases. Before all visits patients had to discontinue their asthma medications for a specified amount of time (short acting $\beta_{2}$ agonists, anticholinergics, cromoglycate: 8 hours; theophylline and oral antihistamines: 24 hours; long acting $\beta_{2}$ agonists: 48 hours). The use of oral and/or inhaled corticosteroids was continued. In the initial 
and two follow up visits, measurements were performed using the same protocol. ${ }^{10-12}$

\section{Questionnaire}

The Dutch version of the British Medical Research Council's standard questionnaire was used which is comparable to the European Coal and Steel Community's questionnaire. ${ }^{13}{ }^{14}$ During the third visit the European Community Respiratory Health Study questionnaire was applied as well. ${ }^{15}$ At all visits subjects were interviewed by a trained physician.

\section{Skin tests, eosinophils, serum IgE}

Intracutaneous skin tests were performed with identical allergen extract batches for house dust, grass pollens, moulds, animal dander, and feather at all visits (Diephuis Laboratory, Groningen, The Netherlands). Since, at the initial visit, the wheal sizes of the skin tests were recorded in $5 \mathrm{~mm}$ categories and the original wheals were no longer available, skin tests were considered positive if the largest diameter of the wheal was at least $5 \mathrm{~mm}$. Blood eosinophils were counted in a Bürker counting chamber (Scherf, Cecchinato, Venice, Italy). At visits 2 and 3, serum total IgE was measured by solid phase immunoassay (Pharmacia IgE EIA, Pharmacia Diagnostics A, Sweden). This test was not available at visit 1 .

\section{Lung function}

Measurements of lung function were carried out with a water sealed spirometer (Lode Spirograph type DL; Lode Instruments, Groningen, The Netherlands). The highest value of two valid measurements of $\mathrm{FEV}_{1}$ and slow inspiratory vital capacity (IVC) was recorded. Predicted values used at visit 1 are those of Zapletal ${ }^{16}$ and at the follow up visits those of the ECCS. ${ }^{17}$

\section{Histamine challenge test}

The method of Tiffeneau as modified by de Vries and Knol was used, ${ }^{18-20}$ as published previously. ${ }^{10-12}$ The histamine concentration causing a decrease of $10 \%$ or more from baseline was taken as threshold value $\left(\mathrm{PC}_{10}\right)$. The test was terminated when the threshold was reached or when the highest concentration had been given. No test was performed in subjects with an $\mathrm{FEV}_{1}<1.5 \mathrm{l}$. Subjects were considered hyperresponsive if their $\mathrm{PC}_{10}$ was $\leqslant 16 \mathrm{mg} / \mathrm{ml}$, a value comparable with $\mathrm{PC}_{20} \leqslant 8 \mathrm{mg} / \mathrm{ml}$ in the 2 minutes inhalation method of Hargreave. ${ }^{21} 22$

\section{Statistical analysis}

"Complete remission" of asthma was defined as having no current wheeze and no asthma attacks in the previous 3 years, no use of inhaled corticosteroids, normal lung function $\left(\mathrm{FEV}_{1}>90 \%\right.$ predicted $)$, and absence of BHR $\left(\mathrm{PC}_{10}>16 \mathrm{mg} / \mathrm{ml}\right)$. "Clinical remission" was defined as absence of wheeze and asthma attacks and no use of inhaled corticosteroids.

Logistic regression analyses were performed to investigate the independent effect of different variables on the two types of asthma remission at visit 3. Based on presumed biological importance, the following explanatory variables were selected a priori to be included in these models: $\mathrm{FEV}_{1} \%$ predicted (per $10 \%$ ) at visit 1 , change in $\mathrm{FEV}_{1} \%$ predicted (per $10 \%$ ) from visit 1 to visit 2 , male sex, $\mathrm{BHR}\left({ }^{2} \log \mathrm{PC}_{10}\right)$ at visit 1 , symptoms of wheeze or asthma attacks at visit $2,{ }^{10} \log$ serum total IgE (IU/l) at visit 2, eosinophilia at visit 1, and smoking habits (pack years) at visit 3. Other logistic regression analyses were performed on the separate components used in defining remission of asthma at visit 3 with the same explanatory variables. All analyses were performed using SPSS (version 11.0.1; SPSS Inc, Chicago, IL, USA).

\section{RESULTS}

From the original cohort of 119 subjects, three were excluded: one subject suffered from $\alpha_{1}$-antitrypsin deficiency and all data for two subjects were missing. Of the remaining 116 patients, 94 attended two follow up examinations, six attended only visit 2 , and six attended only visit 3 . At both visits 2 and 3 the retention rate was 86\%. At visit 2, 14 subjects refused to participate and two were lost to follow up. At visit 3, 11 subjects refused, one could not participate because of pregnancy, two were lost to follow up, and two had moved abroad. The characteristics of the subjects studied and those lost to follow up are given in table 1 . The percentage of males was lowest in the group with no follow up visits. No other significant differences existed between these groups at baseline. At visit 3,91 subjects had complete data and were included in the analysis, while nine only responded to the questionnaire. Baseline characteristics were not significantly different between these groups (results not shown).

Figure 1 shows that 20 of the subjects $(22 \%)$ were in complete remission of asthma at age 32-42 and a further 27 (30\%; total of $52 \%$ ) were in clinical remission. Almost $29 \%$ $(\mathrm{n}=26)$ reported symptoms and, of these patients, $54 \%$ $(n=14)$ did not use inhaled corticosteroids. Finally, 20\% used inhaled corticosteroids without reporting symptoms.

Logistic regression analyses on remission of asthma and its separate components showed that a higher $\mathrm{FEV}_{1} \%$ predicted at visit 1 (aged 5-14 years) and a higher increase in $\mathrm{FEV}_{1} \%$ predicted from visit 1 to 2 (aged 21-33 years) were significantly associated with both complete and clinical remission of asthma at visit 3 (aged 32-42 years; table 2). The odds ratio of 3.02 for $\mathrm{FEV}_{1} \%$ predicted (per 10\%) at visit 1 indicates that the odds of being in complete remission are three times higher for a subject with an $\mathrm{FEV}_{1} \%$ predicted of $90 \%$ at baseline compared with a subject with a baseline $\mathrm{FEV}_{1} \%$

Table 1 Baseline and follow up characteristics of the study population

\begin{tabular}{|c|c|c|c|c|c|}
\hline & \multicolumn{3}{|l|}{ Visit 1} & \multirow{2}{*}{$\begin{array}{l}\text { Visit } 2 \\
(n=100)\end{array}$} & \multirow{2}{*}{$\begin{array}{l}\text { Visit } 3 \\
(n=100)\end{array}$} \\
\hline & $\begin{array}{l}\text { No follow up } \\
\text { visits }(n=10)\end{array}$ & $\begin{array}{l}\text { One follow up visit } \\
\text { (1983 or 1995) } \\
(n=12)\end{array}$ & $\begin{array}{l}\text { Two follow up } \\
\text { visits }(n=94)\end{array}$ & & \\
\hline Mean (SD) age (years) & $9.7(2.2)$ & $9.8(2.1)$ & $9.7(2.0)$ & $26.3(2.5)$ & $37.6(2.2)$ \\
\hline Mean (SD) FEV 1 (\% predicted) & $81.8(17.2)$ & $84.3(12.2)$ & $82.2(17.9)$ & 84.3 (14.7) & $86.1(15.3)$ \\
\hline Mean (SD) FEV ${ }_{1} \% \mathrm{VC}$ & $77.2(10.4)$ & $78.1(8.8)$ & 75.1 (12.3) & $72.1(10.6)$ & $69.6(9.6)$ \\
\hline Sex (\% male) & 30.0 & $91.7^{*}$ & $68.1^{*}$ & 70.0 & 69.0 \\
\hline $\mathrm{PC}_{10} \leqslant 16 \mathrm{mg} / \mathrm{ml}(\%)$ & 80.0 & 100.0 & 80.9 & 29.8 & 51.6 \\
\hline Eosinophilia† (\%) & 25.0 & 63.6 & 43.6 & 30.1 & 29.3 \\
\hline Start symptoms before or at 3 years (\%) & 70.0 & 91.7 & 66.0 & 68.0 & 67.0 \\
\hline
\end{tabular}




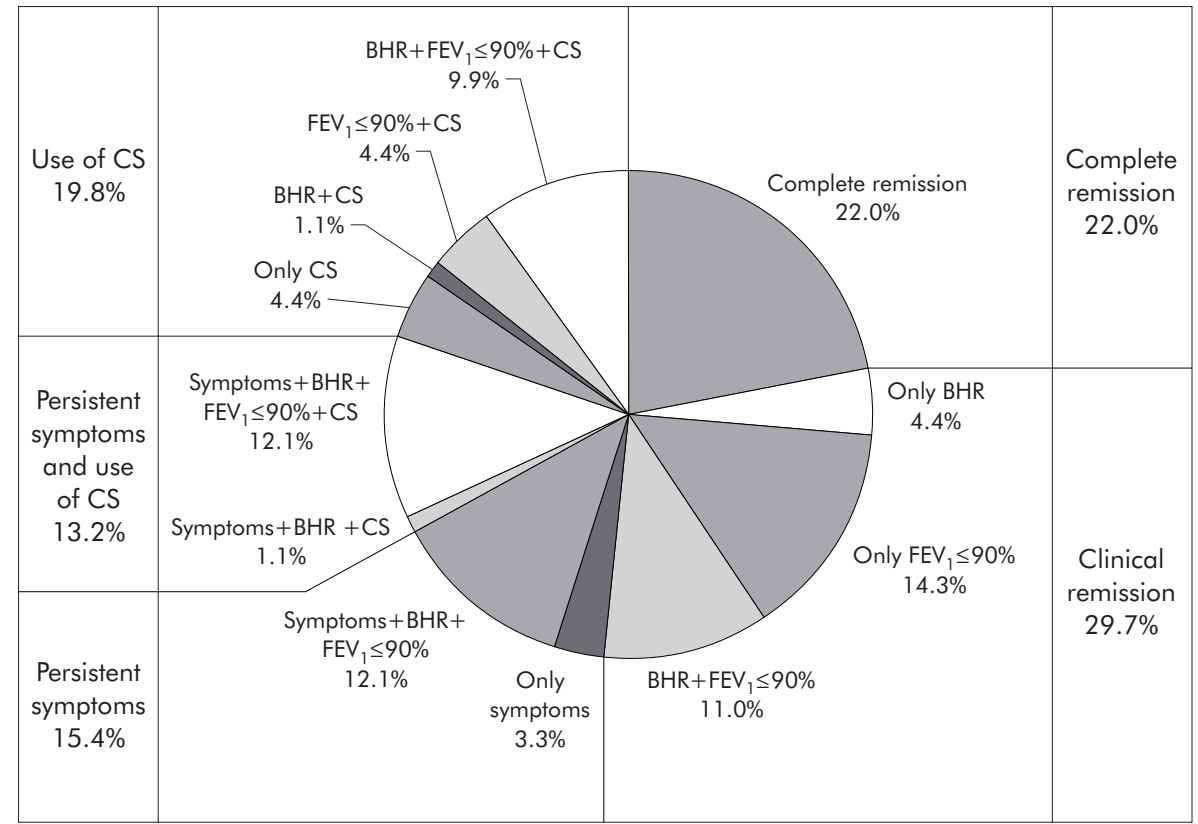

Figure 1 Outcome of childhood asthma at age 32-42 in a longitudinal study of 119 allergic asthmatic children after a follow up of 30 years (91 with a complete dataset). The outcome of asthma is assessed by symptoms of wheeze and/or asthma attacks, use of inhaled corticosteroids (CS), FEV 1 $\leqslant 90 \%$ predicted, and bronchial hyperresponsiveness $\left(\mathrm{PC}_{10} \leqslant 16 \mathrm{mg} / \mathrm{ml} ; \mathrm{BHR}\right)$.

predicted of $80 \%$. Clinical remission was also associated with a higher number of pack years smoked at visit 3. A higher $\mathrm{FEV}_{1} \%$ predicted at visit 1 and a higher increase in $\mathrm{FEV}_{1} \%$ predicted from visit 1 to 2 were also significantly associated with no use of corticosteroids and an $\mathrm{FEV}_{1}>90 \%$ predicted at visit 3. None of the explanatory variables included in the model was significantly associated with the absence of symptoms at visit 3 . A higher number of pack years smoking at visit 3 was significantly associated with no use of corticosteroids at visit 3. Finally, a higher $\mathrm{FEV}_{1} \%$ predicted at visit 1 and a lower serum total IgE at visit 2 were significantly associated with the absence of BHR at visit 3 . Additional adjustment for age at visit 3 did not change these results, nor did removal of lung function parameters from the model cause consistent changes in the estimates of the other covariates.

All patients included had a doctor's diagnosis of asthma, had asthma symptoms, and were atopic. Thirteen subjects did not show BHR at visit 1 . It is possible that some of these were "transient wheezers" and not asthma patients. Re-analysis without these subjects resulted in higher odds ratios (OR) for the ${ }^{2} \log \mathrm{PC}_{10}$ at visit 1 for all outcome parameters studied, which was significant for clinical remission (OR 2.03, 95\% CI 1.03 to 3.99) and for the absence of asthma symptoms at visit 3 (OR 1.83, 95\% CI 1.04 to 3.24) and of borderline significance for complete remission (OR 1.98, 95\% CI 0.96 to $4.09, \mathrm{p}=0.07$ ). Removal of lung function parameters from the model did not change these results.

Figure 2 shows the lung function levels for subjects with persistent asthma and those in complete remission at visit 3. Subjects with persistent asthma showed no improvement in lung function from visit 1 to visit 3: mean $\mathrm{FEV}_{1} \%$ predicted was about $80 \%$ at all visits (table 2). Subjects in complete remission at visit 3 had a near normal $\mathrm{FEV}_{1}$ at all visits: $88.6 \%$ predicted at visit 1 which increased to $96 \%$ at visit 2 and to $101.5 \%$ at visit 3 . The difference in lung function

Table 2 Multiple logistic regression analyses on complete and clinical remission of asthma $†$ at visit 3, on no symptoms $\ddagger$ at visit 3 , on no use of corticosteroids at visit 3 , on $\mathrm{FEV}_{1}>90 \%$ predicted at visit 3 , and on no BHR at visit $3(\mathrm{n}=75)$

\begin{tabular}{|c|c|c|c|c|c|c|}
\hline & $\begin{array}{l}\text { Complete remission* } \\
(n=15 \vee n=60)\end{array}$ & $\begin{array}{l}\text { Clinical remission* } \\
(n=37 \text { v } n=38)\end{array}$ & $\begin{array}{l}\text { No symptoms } \dagger \\
(n=50 \text { v } n=25)\end{array}$ & $\begin{array}{l}\text { No corticosteroid use } \\
(n=51 \vee n=24)\end{array}$ & $\begin{array}{l}\mathrm{FEV}_{1}>90 \% \text { pred } \\
(\mathrm{n}=23 \vee \mathrm{n}=52)\end{array}$ & $\begin{array}{l}\text { No BHR } \\
(n=34 \text { v n=41) }\end{array}$ \\
\hline $\begin{array}{l}\mathrm{FEV}_{1} \% \text { pred visit } 1 \\
\text { (per } 10 \% \text { ) }\end{array}$ & 6671 & $.06)$ & 24) & 2.22 & 34.78) & 1.85 \\
\hline $\begin{array}{l}\mathrm{FEV}_{1} \% \text { pred visit } 2- \\
\text { visit } 1 \text { (per 10\%) }\end{array}$ & 3.08 (1.43 to 6.61$)$ & 2.02 (1.21 to 3.39$)$ & $1.26(0.85$ to 1.87$)$ & 1.66 (1.03 to 2.66$)$ & 5.95 (2.31 to 15.31$)$ & 1.3410 .8 \\
\hline Male sex & to 5.00 ) & 2.50 & 1.73 & 3.5 & 0.3 & $2.34(0.67$ to 8.17$)$ \\
\hline${ }^{2} \log P C_{10}$ visit 1 & $1.14(0.80$ to 1.64$)$ & $1.28(0.91$ to 1.80$)$ & $1.36(0.96$ to 1.91$)$ & $0.95(0.65$ to 1.38$)$ & $1.00(0.66$ to 1.53$)$ & 1.00 (0.74 to 1.37$)$ \\
\hline Symptoms visit $2 \dagger$ & $0.50(0.12$ to 2.19$)$ & $0.62(0.17$ to 2.36$)$ & 0.63 (0.18 to 2.24$)$ & $0.26(0.05$ to 1.29$)$ & $0.97(0.19$ to 4.86$)$ & $0.65(0.20$ to 2.13$)$ \\
\hline $\begin{array}{l}\log \lg E \text { visit } 2 \\
\text { (IU/I) }\end{array}$ & $1.16(0.28$ to 4.77$)$ & 0.33 (0.09 to 1.27$)$ & $0.52(0.15$ to 1.82$)$ & $0.38(0.09$ to 1.64$)$ & $0.49(0.10$ to 2.38$)$ & 0.26 (0.08 to 0.87$)$ \\
\hline Eosinophilic & 2.0 & & & & & 0.8 \\
\hline Pack years visit 3 & $1.00(0.94$ to 1.07$)$ & 1.07 (1.01 to 1.14$)$ & $1.01(0.96$ to 1.06$)$ & 1.09 (1.01 to 1.17$)$ & 1.00 (0.93 to 1.07$)^{\circ}$ & 1.03 (0.98 to 1.09 ) \\
\hline
\end{tabular}

Values are presented as odds ratios with $95 \%$ confidence intervals in parentheses.

${ }^{*}$ Complete remission: no symptoms of wheeze or asthma attacks, no use of inhaled corticosteroids, $\mathrm{FEV} \%$ predicted $>90 \%$, and absence of $\mathrm{BHR}$. Clinical remission: no symptoms of wheeze or asthma attacks, no use of inhaled corticosteroids.

†Symptoms of wheeze and/or asthma attacks.

†Eosinophilia: $0-5$ years: $\geqslant 500 \times 10^{6}$ cells $/ \mathrm{l}, 6-10$ years: $\geqslant 400 \times 10^{6}$ cells $/ \mathrm{l}, 11-15$ years: $\geqslant 350 \times 10^{6}$ cells $/ \mathrm{l},>15$ years: $\geqslant 250 \times 10^{6}$ cells $/ \mathrm{l}$. 


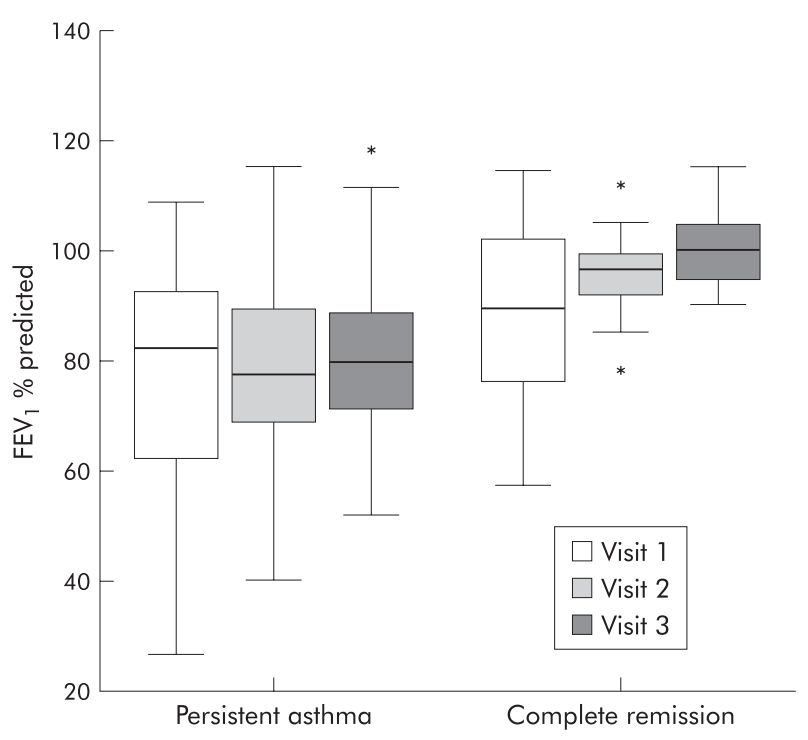

Figure $2 \mathrm{FEV}_{1} \%$ predicted at visits 1, 2, and 3 for subjects with persistent asthma and subjects in complete asthma remission at visit 3 . Complete asthma remission is defined as no symptoms of wheeze and asthma attacks, no use of inhaled corticosteroids, $\mathrm{FEV}_{1}>90 \%$ predicted, no bronchial hyperresponsiveness. Asterisks indicate observations between 1.5 and 3 times the box length (= interquartile range) from the upper or lower edge of the box. Differences between groups (MannWhitney $U$ test): visit $1, p=0.066$; visit $2, p=0.000$; visit $3, p=0.000$.

between subjects with persistent asthma and subjects with asthma in complete remission was statistically significant at visits 2 and 3.

\section{DISCUSSION}

We characterised 119 children with allergic asthma three times over a follow up period of 30 years, 91 of whom (76\%) with a complete dataset at the third visit. The number of individuals with complete asthma remission at the third visit (that is, no asthma symptoms, no steroid use, normal lung function, and no BHR) appeared to be $22 \%$ while a further $30 \%$ (in total $52 \%$ ) was in clinical remission (that is, no asthma symptoms and no steroid use). A higher $\mathrm{FEV}_{1} \%$ predicted in childhood (age 5-14) and a larger increase in $\mathrm{FEV}_{1}$ up to age 21-33 are significantly associated with both complete and clinical remission of asthma at age 32-42 (visit 3).

Studies investigating childhood risk factors for the outcome of asthma usually define remission of asthma in adulthood as a symptom-free state and absence of asthma treatment. With this definition, higher remission rates in adulthood are generally associated with less severe symptoms and better lung function in childhood. ${ }^{323} 24$ Our finding that a better lung function at age 5-14 was significantly associated with both complete and clinical remission of asthma at age $32-42$ is in line with this.

We realise that our cohort is a rather selected group of patients with moderate to severe asthma; it is a clinic based sample of allergic asthmatic children who had to agree to a 5 day stay in hospital at recruitment. We must therefore be cautious in generalising these results to the whole population of asthmatic children. Furthermore, the known role of atopy as a risk factor for the persistence of asthma could not be investigated in this atopic cohort.

Subjects with a lower level of lung function in childhood and a smaller subsequent growth of lung function were likely to have persistent asthma at age 32-42. These deficits in lung function level and its development in early life may be the result of various factors including in utero development and early childhood exposures, but may also reflect airway remodelling shortly after the start of the disease. Unfortunately, at the time of the initial visit (1966-69), inhaled corticosteroids were not available. It can be speculated that lung function deficits would have been smaller if these children had received adequate anti-inflammatory treatment shortly after the start of their disease. ${ }^{25} 26$ Nevertheless, there is a small subgroup of patients with complete asthma remission, despite the absence of inhaled steroid treatment. These patients had only a slightly higher lung function in childhood but their subsequent development in lung function is strikingly better than in patients with persistent asthma. It is possible that the structural changes in the airways caused by airway remodeling in this group did not take place at all, or to a lesser extent.

We also performed an analysis on subjects with BHR at baseline, an indirect marker of airway inflammation. The finding that less severe BHR at baseline is associated with a better outcome of the disease in this subgroup supports the idea of less airway remodelling in those with a better prognosis.

Interestingly, asthmatics who had smoked a higher number of pack years were more likely to be in clinical remission and did not use inhaled corticosteroids at visit 3. This can best be explained by the "healthy smoker effect"that is, those patients with more susceptible airways do not take up smoking or quit early. Alternatively, smokers may have stopped using inhaled corticosteroids, given that smoking is associated with a smaller response to inhaled steroids. ${ }^{27}$ This clearly needs further study.

The absence of asthma symptoms in $71 \%$ of our subjects was not associated with any of the investigated childhood risk factors. Roorda et $a l^{5}$ found that $24 \%$ of their 406 asthmatic children did not report asthma symptoms after a follow up period of nearly 15 years, and none of the investigated childhood risk factors predicted the asymptomatic state, a finding compatible with the results of our study and that of Panhuysen et al. ${ }^{6}$ A comparable prevalence of $28 \%$ symptom-free rate at age $20-24$ has been reported in a prospective childhood asthma study, yet risk factors were not analysed in a multivariate way, preventing appropriate interpretation as to the relevance of the independent risk factors. ${ }^{23}$ To conclude, in children with moderate to severe asthma, childhood asthma status cannot predict whether or not symptoms of wheeze and asthma attacks will still be present in adulthood.

BHR was absent in 44 asthmatics $(48 \%)$ at visit 3 and this was associated with a higher $\mathrm{FEV}_{1} \%$ predicted at visit 1 and a lower total IgE at visit 2. Ulrik and Backer followed 7-17 year old asthmatic children. After 6 years more severe BHR was associated with a lower $\mathrm{FEV}_{1} \%$ predicted and atopy at enrolment. ${ }^{28}$ Two other studies in children, one cross sectional $^{29}$ and the other longitudinal in design, ${ }^{30}$ showed that the prevalence of BHR significantly increased with higher serum total IgE levels. Finally, a study in adults with asthma also showed that higher total IgE was associated with persistence of BHR. ${ }^{6}$ Thus, although the underlying mechanism has yet to be determined, higher IgE levels appear to constitute a risk factor for persistence of BHR.

Twenty of our asthma patients (22\%) were in complete remission of asthma and 47 patients (52\%) were asymptomatic and without inhaled corticosteroids at follow up, a definition used to express clinical remission of asthma. Twenty seven of the latter group (57\%) had BHR or a low lung function, or both. This is in line with the study of Boulet et $a l^{7}$ who found that asymptomatic asthmatic subjects who did not use medication still had active disease, as shown by lower lung function values, increased bronchodilator response, and BHR suggesting either ongoing airway 
inflammation or airway remodelling. Indeed, a recent study ${ }^{8}$ showed that asthma patients with a comparable definition of remission ${ }^{7}$ had higher numbers of eosinophils, $\mathrm{T}$ cells, mast cells, and IL-5 in the airway mucosa than healthy control subjects. Another study ${ }^{31}$ found higher numbers of eosinophils in the bronchoalveolar lavage fluid of atopic children who had apparently outgrown their asthma (no wheezing for 12 months and no current medication) compared with controls. Thus, simply asking patients whether they have asthma symptoms and use asthma treatment is unreliable for determining airway inflammation as well as asthma remission. It remains to be established whether this has consequences for clinical practice-that is, institution of anti-inflammatory treatment.

We conclude that complete remission of asthma is only present in a small subset of this clinic based sample of atopic patients with moderate to severe asthma. Importantly, we show variable results in the outcome of asthma dependent on whether remission is defined as absence of symptoms, (near) normal lung function, absence of BHR, no use of asthma medication, or as a combination of these components. Only $22 \%$ of symptomatic allergic asthmatic children fully outgrew their asthma by age 32-42, determined on the basis of a combination of objective and subjective measurements. Remission of asthma is associated with better lung function early in life and a higher increase in lung function from age $5-14$ to age $21-33$. This possibly reflects a lower prevalence of early and/or progressive airway remodelling in those patients with a better outcome of the disease. Our results support the idea that defining remission of asthma by only assessing symptoms and medication use will overlook those subjects who have subclinical active disease and possibly associated airway remodelling.

\section{Authors' affiliations}

J M Vonk, H M Boezen, J P Schouten, Department of Epidemiology, University of Groningen, The Netherlands

D S Postma, G H Koëter, Department of Pulmonology, University Hospital and University of Groningen, The Netherlands

M H Grol, J Gerritsen, Department of Pediatric Pulmonology, University Hospital and University of Groningen, The Netherlands

This study was supported by The Netherlands Asthma Foundation (grant number 93.64) and Stichting Astma Bestrijding.

\section{REFERENCES}

1 Martin AJ, Mclennan LA, Landau LI, et al. The natural history of childhood asthma to adult life. BMJ 1980;280:1397-400

2 Phelan PD, Robertson CF, Olinsky A. The Melbourne asthma study: 19641999. J Allergy Clin Immunol 2002;109:189-94.

3 Bronnimann S, Burrows B. A prospective study of the natural history of asthma. Chest 1986;90:480-4.

4 Sears MR, Greene JM, Willan AR, et al. A longitudinal, population-based, cohort study of childhood asthma followed to adulthood. N Engl J Med 2003;349:1414-22.

5 Roorda RJ, Gerritsen J, van Aalderen WMC, et al. Risk factors for the persistence of respiratory symptoms in childhood asthma. Am Rev Respir Dis 1993;148:1490-5.
6 Panhuysen CIM, Vonk JM, Koëter GH, et al. Adult patients may outgrow their asthma. A 25 year follow-up study. Am J Respir Crit Care Med 1997; 155:1267-72

7 Boulet L-P, Turcotte $\mathrm{H}$, Brochu A. Persistence of airway obstruction and hyperresponsiveness in subjects with asthma remission. Chest 1994; 105:1024-31

8 van den Toorn LM, Overbeek SE, de Jongste JC, et al. Airway inflammation is present during clinical remission of atopic asthma. Am J Respir Crit Care Med 2001;164:2107-13

9 van Lookeren Campagne JG, Knol K, de Vries K. House dust provocation in children. Scand J Respir Dis 1969;50:76-85.

10 Gerritsen J, Koëter GH, Postma DS, et al. Prognosis of asthma from childhood to adulthood. Am Rev Respir Dis 1989;140:1325-30.

11 Grol MH, Postma DS, Vonk JM, et al. Risk factors from childhood to adulthood for bronchial responsiveness at age 32-42 yr. Am J Respir Crit Care Med 1999;160:150-6.

12 Grol MH, Gerritsen J, Vonk JM, et al. Risk factors for growth and decline of lung function in asthmatic individuals up to age 42 years. A 30 year follow-up study. Am J Respir Crit Care Med 1999;160:1830-7.

13 van der Lende R, Orie NGM. The MRC-ECCS questionnaire on respiratory symptoms (use in epidemiology). Scand J Respir Dis 1972;53:218-26.

14 Kerrebijn KF, Hoogeveen-Schroot HCA, van der Wal MC. Chronic nonspecific respiratory disease in children: a five year follow-up study. Acta Paediatr Scand Suppl 1977;261:1-72.

15 Burney PGJ, Luczynska C, Chinn S, et al. The European community respiratory health survey. Eur Respir J 1994;7:954-60.

16 Zapletal A, Samanek M, Paul T. Lung function in children and adolescents. Methods, reference values. In: Zapletal A, ed. Progress in Respiration Research 1987;22:114-16.

17 Quanjer PhH, Tammeling GJ, Cotes JE, et al. Lung volumes and forced ventilatory flows. Report working party standardization of lung function test European Community for Steel and Coal. Official statement of the European Respiratory Society. Eur Respir J 1993;6:5-40.

18 de Vries K, Goei JT, Booy-Noord H, et al. Changes during 24 hours in the lung function and histamine hyperreactivity of the bronchial tree in asthmatic and bronchitic patients. Int Arch Allergy 1962;20:93-101.

$19 \mathrm{Knol} \mathrm{K.} \mathrm{A} \mathrm{clinical} \mathrm{and} \mathrm{epidemiological} \mathrm{study} \mathrm{of} \mathrm{the} \mathrm{significance} \mathrm{of} \mathrm{bronchial}$ hyperreactivity in children with nonspecific lung disease (CNSLD). Thesis, The Netherlands: University of Groningen, 1965.

20 Eiser NM, Kerrebiin KF, Quanjer PhH. Guidelines for standardization of bronchial challenges with (nonspecific) bronchoconstricting agents. Bull Eur Physiopathol Respir 1983;19:495-514

21 Rijcken B, Schouten JP, Weiss ST, et al. The distribution of bronchial responsiveness to histamine in symptomatic and in asymptomatic subjects. A population-based analysis of various indices of responsiveness. Am Rev Respir Dis 1989;140:615-23.

22 Cockcroft DW, Berscheid BA. Standardization of inhalation provocation tests. Dose vs concentration of histamine. Chest 1982;82:572-5.

23 Kokkonen J, Linna O. The state of childhood asthma in young adulthood. Eur Respir J 1993;6:657-61

24 Godden DJ, Ross S, Abdalla M, et al. Outcome of wheeze in childhood. Symptoms and pulmonary function 25 years later. Am J Respir Crit Care Med 1994; 149:106-12.

25 Agertoft L, Pedersen S. Effects of long-term treatment with an inhaled corticosteroid on growth and pulmonary function in asthmatic children. Respir Med 1994:88:373-81.

26 Selroos $\mathrm{O}$, Pietinalho $A$, Löfroos $A-B$, et al. Effect of early vs late intervention with inhaled corticosteroids in asthma. Chest 1995; 108:1228-34.

27 Chalmers GW, MacLeod KJ, Little SA, et al. Influence of cigarette smoking on inhaled corticosteroid treatment in mild asthma. Thorax 2002;57:226-30.

28 Ulrik CS, Backer V. Longitudinal determinants of bronchial responsiveness to inhaled histamine. Chest 1998;113:973-9.

29 Sears MR, Burrows B, Flannery EM, et al. Relation between airway responsiveness and serum lgE in children with asthma and in apparently normal children. N Engl J Med 1991;325:1067-71.

30 Burrows B, Sears MR, Flannery EM, et al. Relation of the course of bronchial responsiveness from age 9 to 15 to allergy. Am J Respir Crit Care Med 1995; 152:1302-8.

31 Warke TJ, Fitch PS, Brown V, et al. Outgrown asthma does not mean no airways inflammation. Eur Respir J 2002;19:284-7. 